\title{
Enzymes for biosynthesis de novo and elongation of fatty acids in mycobacteria grown in host cells: is Mycobacterium leprae competent in fatty acid biosynthesis?
}

\author{
Paul R. Wheeler, ${ }^{*}$ Kath Bulmer and Colin Ratledge \\ Department of Applied Biology, University of Hull, Hull HU6 7RX, UK
}

(Received 16 June 1989; revised 25 September 1989; accepted 9 October 1989)

\begin{abstract}
Fatty acid synthetase activity in extracts of Mycobacterium leprae was equivalent to 1.7 pmol malonyl-CoA incorporated into fatty acid min $^{-1}$ (mg protein) $)^{-1}$. This activity - if representative of living $M$. leprae organisms - is insufficient to enable them to synthesize their lipid requirements rapidly enough to support growth. The major activity for scavenging fatty acids in extracts of Mycobacterium microti and Mycobacterium avium, as well as in extracts of $M$. leprae, was acetyl-CoA-dependent fatty acyl-CoA 'elongase'. This activity was about four times higher in $M$. avium and $M$. microti grown in a medium which contained lipids, or when grown in mice, than in medium without added lipids. In contrast, the de novo fatty acid synthetase activity was repressed in $M$. avium and $M$. microti when grown in medium that contained lipids, or when grown in mice. These results are consistent with the hypothesis that mycobacteria grown in vivo preferentially scavenge lipids from the host cells, and suggest that a source of lipid should be included in media for attempted axenic isolation of $M$. leprae.
\end{abstract}

\section{Introduction}

Mycobacterium leprae, the causative agent of leprosy, has been observed to divide only inside host cells (Mor, 1983; Mukherjee \& Antia, 1985). To date, there is no authenticated report of its axenic culture. Thus, as an obligate, intracellular parasite it may lack a number of biosynthetic capabilities, making it dependent upon its environment for certain intermediates. For instance, $M$. leprae cannot synthesize the purine ring de novo, an activity which is readily observed in other host-grown mycobacteria (Wheeler, $1987 a, b$ ). The main purpose of the present work is to ascertain whether or not $M$. leprae can synthesize fatty acids de novo.

Intact $M$. leprae organisms do not incorporate carbon from simple carbon sources into fatty acids (Wheeler \& Ratledge, 1988). This might indicate a deficiency in their ability to synthesize fatty acids but de novo fatty acid biosynthesis is subject to strong metabolic control in mycobacteria: when fatty acids are available, repression (Ascenzi \& Vestal, 1979) and feedback inhibition (Bloch, 1977) occur. Therefore, in this study, de novo fatty acid synthesis was assayed in $M$. avium and $M$. microti grown in vivo, as well as axenically with and without an exogenous source of lipid. In this way, results obtained with $M$. leprae can be interpreted in the light of the information obtained on control of fatty acid biosynthesis in other intracellular mycobacteria.

Also, since it is likely that lipids, containing fatty acyl moieties, will be available from the host cells themselves to intracellular mycobacteria (Barclay \& Wheeler, 1989; Wheeler \& Ratledge, 1988), activities for elongating existing fatty acids (which might be obtained from host lipids) were determined in $M$. leprae, $M$. avium and $M$. microti.

\section{Methods}

Mycobacteria used and their growth. M. leprae, M. microti OV254 and $M$. avium CR 1/69 were grown in host tissue, and harvested as described previously using a method (World Health Organization, 1980) which has proved successful for isolating purified suspension of mycobacteria for metabolic studies (Wheeler, 1987a). M. microti OV254, M. avium CR 1/69 and $M$. smegmatis NCIB 8548 were also grown in $100 \mathrm{ml}$ of Dubos medium (Chadwick, 1982) in $250 \mathrm{ml}$ flasks, shaken at 200 r.p.m. in a rotary shaker/incubator at $37^{\circ} \mathrm{C}$ and harvested (Wheeler, 1987a) after $15 \mathrm{~d}, 18 \mathrm{~d}$ and $5 \mathrm{~d}$ respectively. Some batches of $\boldsymbol{M}$. microti and $\boldsymbol{M}$. avium were grown in the presence of added lipids, either sodium palmitate $(100 \mu \mathrm{g}$ per $\mathrm{ml}$ of medium) or liposomes containing phosphatidylcholine (from egg-yolk; $99 \%$ pure, containing mainly palmitoyl and stearoyl acyl moieties) plus cholesterol, and $s n-1,2-$ dipalmitoylphosphatidic acid in the molar ratio 10:10:1, prepared by the method of Kondo et al. (1985), and totalling $150 \mu \mathrm{g}$ lipid per $\mathrm{ml}$ of medium. All biochemicals were from Sigma. 
Preparation of cell-free extracts of mycobacteria. Mycobacteria were disrupted ultrasonically with a Dawe soniprobe type 75324 at $100 \mathrm{~W}$ using short bursts ( 45 to $75 \mathrm{~s}$ ) for a total of $11 \mathrm{~min}$, and keeping the material at $0{ }^{\circ} \mathrm{C}$ during the intervals. The protocol was essentially that of Wheeler \& Gregory (1980) except that the buffer used to suspend the bacteria was $0.2 \mathrm{M}$-potassium phosphate, $\mathrm{pH} 7$, with $5 \mathrm{~mm}$ dithiothreitol. The sonicate was clarified by centrifuging once at $20000 \mathrm{~g}$ for $10 \mathrm{~min}$. The resulting extract was used immediately as fatty acid synthetase activity was rapidly lost. Attempts to store extracts are described in the section in Results on stability of activities.

Some assays were always done with extracts which had been desalted by passing through Amicon ultrafiltration cones (cut-off $M_{\mathrm{r}}, 25000$ ), but no differences were observed in activities between desalted extracts and extracts that had not been desalted.

Assays for enzyme systems. (All enzyme activities assayed in this paper are multi-enzyme complexes and EC numbers therefore do not apply.) Activities assayed (Table 1) were de novo fatty acid synthetase and malonyl-CoA-dependent, fatty acyl-CoA elongating activity (methods based on Bloch, 1975; Medhi et al., 1979), and acetyl-CoAdependent, fatty acyl-CoA elongating activity (Kusaka, 1977). $\left[2-{ }^{14} \mathrm{C}\right]$ Malonyl-CoA $\quad\left(2.15 \mathrm{TBq} \mathrm{mol}^{-1}\right)$ or $\left[1-{ }^{-14} \mathrm{C}\right]$ acetyl-CoA ( $\left.2.05 \mathrm{TBq} \mathrm{mol}^{-1}\right)$ (supplied by Amersham) were used and all activities were calculated as pmol malonyl-CoA or acetyl-CoA incorporated into fatty acid $\min ^{-1}$ (mg protein $)^{-1}$ in the presence of a primer. The primers were acetyl-CoA (lithium salt) for the de novo synthetase and decanoyl-CoA or palmitoyl-CoA (free acids) for the 'elongases' (Table 1); assay mixtures with no primers were used as controls. In Tables 3 to 5 , a single value is presented for each activity where malonyl-CoA is incorporated, although separate assays were done in which $\alpha$ cyclodextrin or acyl-carrier protein (Sigma; from E. coli) or neither $\alpha$ cyclodextrin, nor acyl-carrier protein were included. The single values for each activity in Table 3 to 5 were generated as follows: every time a cell-free extract was made, all the assays shown in Table 1 were done, and for the three malonyl-CoA-dependent activities (de novo synthesis, decanoyl-CoA-dependent elongation and palmitoyl-CoA-dependent elongation) the maximum activity obtained - either with $\alpha$-cyclodextrin, with acyl-carrier protein or with neither addition - was noted. Then the means of the maximum activities obtained in this way with several (see Table 1) extracts were calculated, and presented as the values in Tables 3 to 5. For example, activity of de novo fatty acid synthetase was calculated by taking the maximum of the three values obtained by subtracting radioactivity incorporated in assay 11 from assay 1,12 from 2 or 13 from 3 . Radioactivity incorporated in the controls was as follows: with $\left[{ }^{14} \mathrm{C}\right]$ malonyl-CoA, assays 11 to 13 in Table 1 , around $15 \%$ of the radioactivity when primers were included (assays 1 to 8 ); with $\left[{ }^{4} \mathrm{C}\right]$ acetyl-CoA (assay 14 ), 5 to $10 \%$ of the radioactivity when primers were included (assays 9 and 10). This background incorporation could reflect small quantities of endogenous fatty acid or fatty acyl-CoA. Complete assay mixtures included buffer, NADH ( $\beta$-NADH, disodium salt), NADPH ( $\beta$-NADH, trisodium salt), FMN (flavin mononucleotide, sodium salt), coenzyme-A (lithium salt) - all from Sigma - as specified in Table 1. Activity from all assay mixtures $(500 \mu \mathrm{l})$ was determined by taking samples $(225 \mu \mathrm{l})$ at 15 or $25 \mathrm{~min}$ and $50 \mathrm{~min}$, saponifying each mixture with $190 \mu \mathrm{l} 40 \%$ (w/v) $\mathrm{KOH}$ ior $30 \mathrm{~min}$ at $100^{\circ} \mathrm{C}$, acidifying with $11.6 \mathrm{M}-\mathrm{HCl}(160 \mu \mathrm{l}$ was usually sufficient) to $\mathrm{pH} 2$ (using methyl orange as indicator) and extracting three times with $5 \mathrm{ml}$ light petroleum (b.p. $30-40{ }^{\circ} \mathrm{C}$ ). The solvent extracts were pooled in scintillation vials and $30 \mu \mathrm{l}$ glacial acetic acid was added. Any contaminating aqueous phase, visible due to its colouration with indicator, was removed, and the light petroleum extract was then dried at $25^{\circ} \mathrm{C}$. Bray's scintillation fluid was added to each residue and radioactivity was determined by liquid-scintillation counting.

\section{Table 1. Assay mixtures for fatty acid synthetase and elongases}

Routinely, each mycobacterial extract prepared was incubated at $34{ }^{\circ} \mathrm{C}$ with all the assay mixtures (final volume $500 \mu \mathrm{l}$ ) shown below. Two or three extracts were prepared from each of $M$. leprae, and from both $M$. microti OV 254 and $M$. avium CR $1 / 69$ grown in each of the media shown in Table 3. Additionally, extracts of $M$. smegmatis NCIB 8548 were assayed for de novo fatty acid synthetase only - in a typical extract, the specific activity was $338 \mathrm{pmol}$ malonyl-CoA incorporated into fatty acid $\mathrm{min}^{-1}$ (mg protein) ${ }^{-1}$. Also, two extracts of $M$. leprae were assayed for fatty acid synthetase only, but with $22 \cdot 2 \mathrm{kBq}\left[2-{ }^{14} \mathrm{C}\right]$ malonyl-CoA per assay mixture. Generally, duplicate assays were done with each assay mixture. Extracts contained 0.5 to $6 \mathrm{mg}$ protein $\mathrm{ml}^{-1}$; when sufficient extract at $\geqslant 0.5 \mathrm{mg}$ protein $\mathrm{ml}^{-1}$ was unavailable to add to all the assay mixtures in duplicate, some assays were done once only. Determination of activity is described in Methods.

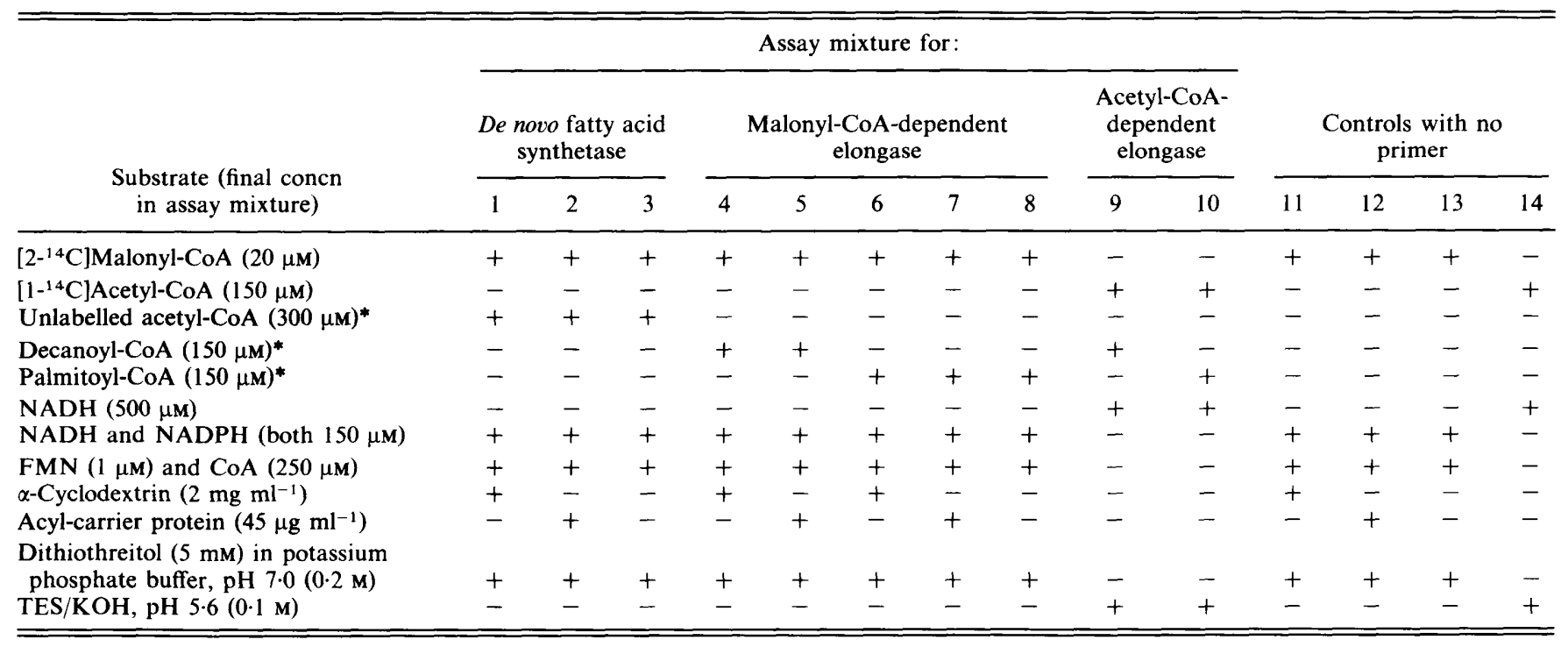


Separation of malonate, acetate and their CoA-esters. Samples $(10 \mu 1)$, taken after $50 \mathrm{~min}$ from assay mixtures (Table 1), were applied to TLC plates (Eastman-Kodak cellulose TLC plates) together with $20 \mu \mathrm{g}$ of malonyl-CoA, of acetyl-CoA and of malonate, and $50 \mu \mathrm{g}$ of acetate (as lithium salts), and allowed to dry at $25^{\circ} \mathrm{C}$. Plates were developed in propan-2-ol/distilled water $(4: 1, \mathrm{v} / \mathrm{v})$, then partially dried at $25^{\circ} \mathrm{C}$, and sprayed with $0.04 \%$ Bromocresol Blue in ethanol/water $(96: 4, \mathrm{v} / \mathrm{v})$. Spots corresponding to the four compounds were cut-out, placed in vials, and their radioactivity determined by liquid-scintillation counting using Bray's scintillation fluid.

\section{Results}

Optimizing conditions for enzyme assays

The assays used routinely in this work are shown in Table 1 ; they include many modifications of the assays in the literature (see Methods; assays for enzyme systems) to facilitate detection of what often proved to be low and unstable activities. This section describes how the assays in Table 1 were devised and the following two sections describe how possible artifacts were ruled out.

For optimizing assays, extracts of mycobacteria grown in Dubos medium were used. Activity of de novo fatty acid synthetase detected in extracts with $150 \mu \mathrm{M}-\mathrm{NADH}$ plus $150 \mu \mathrm{M}-\mathrm{NADPH}$ was 2 -fold higher for $M$. avium and 1.3-fold higher for $M$. microti than activity using the reduced coenzymes each at $30 \mu \mathrm{M}$. No further increase in activity was obtained by recycling reduced coenzymes by adding $1 \mathrm{~mm}$-glucose 6-phosphate (monosodium salt) and $0.3 \mathrm{U}$ glucose-6-phosphate dehydrogenase $\mathrm{ml}^{-1}$. (This enzyme, from Leuconostoc mesenteroides, uses either $\mathrm{NAD}^{+}$or $\mathrm{NADP}^{+}$and was purchased from Sigma.) When assays were done at pH 5.6 instead of $\mathrm{pH} 7 \cdot 0$, activity of both de novo fatty acid synthetase and malonyl-CoA-dependent, fatty acyl-CoA elongase (in the presence of $\alpha$-cyclodextrin) in extracts of $M$. smegmatis, $M$. microti or $M$. avium was 25 to $35 \%$ of the activity at $\mathrm{pH} 7 \cdot 0$. A buffer concentration of $0.2 \mathrm{M}$ had to be used; at a buffer concentration of $10 \mathrm{mM}$, virtually no malonyl-CoA-dependent activities were detected though acetyl-CoA-dependent, acyl-CoA elongating activity was readily detected (Table 2 ).

\section{Contamination with activity from host-derived enzymes}

All the mean values presented in Tables 3 to 5 for activities in host-grown mycobacteria include results obtained with extracts of host-grown mycobacteria treated with $0.5 \mathrm{M}-\mathrm{NaOH}$ for $30 \mathrm{~min}$ to abolish hostderived activities (Wheeler et al., 1982). No marked difference was observed for any activities between extracts from untreated and $\mathrm{NaOH}$-treated mycobacteria grown in vivo. However, no de novo fatty acid synthetase activity could be detected in the supernatant of homogenized infected host tissue (which had been centrifuged to collect the bacteria as a pellet) so it appears that host-derived synthetase activity is destroyed during the procedure for harvesting the mycobacteria.

Table 2. Effect of ionic strength on fatty acid synthetase and elongases

Extracts of $\boldsymbol{M}$. smegmatis and $\boldsymbol{M}$. microti grown in Dubos medium were prepared as described in Methods, either in $0.2 \mathrm{M}$-potassium phosphate buffer, $\mathrm{pH} \mathrm{7,} \mathrm{with} 5 \mathrm{~mm}$-dithiothreitol, or in $10 \mathrm{~mm}$ $\mathrm{MES} / \mathrm{KOH}, \mathrm{pH} 7$, with $1 \mathrm{mM}-\mathrm{MgCl}_{2}$. Relative activities of the extracts, determined in duplicate, are shown in this Table. Specific activities, when assays were done with the mixtures shown in Table 1 , and for which the assigned value for relative activity is 100 , are given in Tables 4 to 6 for $M$. microti. For $M$. smegmatis, the specific activities in a typical extract were: de novo synthetase, $338 \mathrm{pmol} \mathrm{min}^{-1} \mathrm{mg}$ (protein) ${ }^{-1}$; malonyl CoA-dependent palmitoyl-CoA elongase, $252 \mathrm{pmol} \mathrm{min}^{-1}$ $(\mathrm{mg} \text { protein })^{-1}$; acetyl-CoA-dependent palmitoyl-CoA elongase, $40 \mathrm{pmol} \mathrm{m^{-1 }}$ (mg protein) ${ }^{-1}$.

\begin{tabular}{|c|c|c|c|c|c|}
\hline \multirow[b]{3}{*}{ Activity } & \multirow[b]{3}{*}{$\begin{array}{l}\text { Assay } \\
\text { buffer }\end{array}$} & \multicolumn{4}{|c|}{ Extract } \\
\hline & & \multicolumn{2}{|c|}{ M. smegmatis in: } & \multicolumn{2}{|c|}{ M. microti in: } \\
\hline & & $\begin{array}{l}10 \mathrm{~mm} \\
\text { buffer }\end{array}$ & $\begin{array}{c}0 \cdot 2 \mathrm{M} \\
\text { buffer* }\end{array}$ & $\begin{array}{l}10 \mathrm{mM} \\
\text { buffer }\end{array}$ & $\begin{array}{c}0.2 \mathrm{M} \\
\text { buffer* }\end{array}$ \\
\hline De novo synthetase & $\begin{array}{r}10 \mathrm{mM} \\
0.2 \mathrm{M}\end{array}$ & $\begin{array}{l}2 \\
0(<0 \cdot 3)\end{array}$ & $\begin{array}{l}\text { ND } \\
100\end{array}$ & $\begin{array}{l}0(<0 \cdot 6) \\
0(<0 \cdot 6)\end{array}$ & $\begin{array}{l}\text { ND } \\
100\end{array}$ \\
\hline $\begin{array}{l}\text { Malonyl-CoA-dependent } \\
\text { palmitoyl-CoA elongase }\end{array}$ & $\begin{array}{r}10 \mathrm{mM} \\
0 \cdot 2 \mathrm{M}\end{array}$ & $\begin{array}{l}0(<0.4) \\
\text { ND }\end{array}$ & $\begin{array}{l}\text { ND } \\
100\end{array}$ & $\begin{array}{c}0(<0 \cdot 9) \\
\text { ND }\end{array}$ & $\begin{array}{l}\text { ND } \\
100\end{array}$ \\
\hline $\begin{array}{l}\text { Acetyl-CoA-dependent } \\
\text { palmitoyl-CoA elongase }\end{array}$ & $\begin{array}{r}10 \mathrm{mM} \\
0.1 \mathrm{M}\end{array}$ & $\begin{array}{r}95 \\
105\end{array}$ & $\begin{array}{l}\text { ND } \\
100\end{array}$ & $\begin{array}{r}110 \\
98\end{array}$ & $\begin{array}{l}\mathrm{ND} \\
100\end{array}$ \\
\hline
\end{tabular}

ND, Not done.

* Low ionic strength could not be achieved in assays of extracts made in $0.2 \mathrm{M}$ buffer. 


\section{Hydrolysis and decarboxylation of CoA-esters during incubation with assay mixtures}

Formation of acetyl-CoA and malonate from malonyl$\mathrm{CoA}$, and acetate from acetyl-CoA was determined in all the assay mixtures shown in Table 1. At the worst, in all the assays with $M$. microti, $M$. avium and $M$. leprae, $15 \%$ of the radioactivity from $\left[{ }^{14} \mathrm{C}\right]$ malonyl-CoA and $7 \%$ of the radioactivity from $\left[{ }^{14} \mathrm{C}\right]$ acetyl-CoA could be traced into free acids. Additionally, after incubation with $\left[{ }^{14} \mathrm{C}\right]$ malonyl-CoA, up to $6 \%$ of the radioactivity could be detected in acetyl-CoA. Both of these 'worst-cases' occurred with $M$. microti grown either in Dubos medium or Dubos medium plus $100 \mu \mathrm{g}$ palmitate $\mathrm{ml}^{-1}$. As at worst only $21 \%$ of the malonyl-CoA is depleted during these assays, it is unlikely that any of the activities in Tables 2 to 5 are substantially affected by metabolism of the CoA-esters by enzymes competing with those under study.

\section{Stability of fatty synthetase and malonyl-CoA-dependent} elongase activity

Extracts of $M$. smegmatis, stored for $2 \mathrm{~d}$ at either $-20^{\circ} \mathrm{C}$ or $4{ }^{\circ} \mathrm{C}$, contained $<3 \%$ of the activity in freshly prepared extracts. Addition of $\alpha$-cyclodextrin (at $2 \mathrm{mg} \mathrm{ml}^{-1}$ ) and a 'cocktail' of protease inhibitors (phenylmethylsulphonyl fluoride at $4 \mu \mathrm{g} \mathrm{ml}^{-1}, N \alpha-p$ tosyl-L-lysine chloromethyl ketone at $12 \mu \mathrm{g} \mathrm{ml}^{-1}$ and $1 \mathrm{~mm}$-benzamidine) to the suspension prior to sonication did not improve the stability of the activity; neither did addition of any one of the compounds alone. Disruption of a suspension of $M$. smegmatis (by three passages at $35 \mathrm{MPa}$ through a French press precooled to $4{ }^{\circ} \mathrm{C}$ ) resulted in an extract with $60 \%$ of the activity of an extract prepared in parallel by ultrasonic disruption. Subsequently, an extract of $M$. microti stored at $4{ }^{\circ} \mathrm{C}$ for $5 \mathrm{~h}$ was shown to contain only $20 \%$ of the activities of $d e$ novo fatty acid synthetase and malonyl-CoA-dependent fatty acid elongase that were detected in the same extract when assayed immediately.

\section{Fatty acid synthetase and elongase activity in $M$. leprae}

Extracts of $M$. leprae contained barely detectable de novo fatty acid synthetase activity. With $3.7 \mathrm{kBq}\left[{ }^{14} \mathrm{C}\right]-$ malonyl-CoA per assay, the limit of detection is $\sim 0.8 \mathrm{pmol}$ incorporated $\mathrm{min}^{-1}$. However, by including $22.2 \mathrm{kBq}$ per assay, the limit of detection could be improved to $\sim 0.2 \mathrm{pmol}$ incorporated $\mathrm{min}^{-1}$. By using this modification and by using extracts immediately after preparation, the trace of activity (Table 3 ) could be detected consistently.
Fatty acid elongating activities, important in the utilization of fatty acids, were detected in $M$. leprae. Extracts contained malonyl-CoA-dependent fatty acid elongating activity at very low specific activities, similar to the activity detected for the synthetase (Table 3). However, an acetyl-CoA-dependent fatty acid elongating activity was present at about 100 times the activity of the malonyl-CoA-dependent activity (Table 2). Either acyl-carrier protein or $\alpha$-cyclodextrin had to be added to assay mixtures to give maximal rates of the malonylCoA-dependent synthetase or elongase activities in Table 3.

Fatty acid synthetase and its regulation in $M$. microti and M. avium

Metabolic control of fatty acid synthetase was apparent in both $M$. microti and $M$. avium (Table 4). Specific activities of fatty acid synthetase were respectively 7 -fold and 5-fold lower in extracts from host-grown bacteria than from the bacteria grown in Dubos medium. Inhibition or repression also occurred when these pathogenic mycobacteria were grown in the presence of lipids (details of lipids added to the culture medium are presented in Methods, and briefly in Table 4). Thus, fatty

Table 3. Fatty acid synthetase and elongases in $M$. leprae

$M$. leprae organisms were harvested from armadillo tissue. Assay mixtures and conditions were as in Table 1 . Values (means \pm SEM) are pmol $\mathrm{C}_{2}$-source incorporated into fatty acid $\mathrm{min}^{-1}(\mathrm{mg}$ protein $)^{-1}$

\begin{tabular}{lcc}
\hline \hline & \multicolumn{2}{c}{$\begin{array}{c}\mathrm{C}_{2} \text {-source (which includes } \\
{ }^{14} \mathrm{C} \text {-labelled material) }\end{array}$} \\
\cline { 2 - 3 } Primer & Malonyl-CoA & Acetyl-CoA \\
\hline Acetyl-CoA & $1 \cdot 7 \pm 0 \cdot 5^{*}$ & Not determined \\
Decanoyl-CoA & $3 \cdot 0 \pm 1 \cdot 5$ & $341 \pm 74$ \\
Palmitoyl-CoA & $1 \cdot 0 \pm 0 \cdot 4$ & $159 \pm 68$ \\
\hline \hline
\end{tabular}

* De novo synthetase; other activities represent elongases.

Table 4. Fatty acid synthetase in $M$. microti and $M$. avium

Assay mixtures and conditions were as in Table 1. Values (means \pm SEM) are pmol malonyl-CoA incorporated into fatty acid $\mathrm{min}^{-1}$ $(\mathrm{mg} \text { protein })^{-1}$.

\begin{tabular}{lcc}
\hline \hline \multirow{2}{*}{$\begin{array}{c}\text { Growth } \\
\text { medium }\end{array}$} & \multicolumn{2}{c}{ Extract from: } \\
\cline { 2 - 3 } & $M$. microti OV254 & M. avium CR1/69 \\
\hline Dubos & $139 \pm 30$ & $153 \pm 22$ \\
Dubos + palmitate & $3 \pm 2$ & $8 \pm 3$ \\
Dubos + liposomes & $8 \pm 3$ & Not determined \\
Mice & $18 \pm 6$ & $32 \pm 11$ \\
\hline \hline
\end{tabular}


acid synthetase activity in extracts of $M$. microti and $M$. avium prepared from bacteria grown in Dubos medium plus lipids was, respectively, 17 - to 46 -fold and 19-fold lower than in extracts from those bacteria grown in Dubos medium alone (Table 4). This cannot be explained by differences in growth as rate of growth was not affected by addition of lipid in the case of $M$. avium. In $M$. microti, the growth rate was stimulated $(P<0 \cdot 01)$ by the addition of liposomes. However, growth was inhibited by adding palmitate. Flasks were inoculated with $0.3 \mathrm{mg}$ dry wt bacteria and after $15 \mathrm{~d}$ the yields were as follows: $33 \cdot 1 \pm 1 \cdot 1$ (SEM) mg dry wt in Dubos medium alone; $40 \cdot 3 \pm 1 \cdot 4$ (SEM) mg dry wt in Dubos medium plus liposomes; and, typically, $\sim 15 \mathrm{mg}$ dry wt in Dubos medium, plus palmitate. (Details of lipids added and growth conditions are in Methods).

To obtain the maximal activities of fatty acid synthetase for $M$. microti (as shown in Table 4) $\alpha$-cyclodextrin had to be added to assay mixtures on eight occasions out of ten when fatty acid synthetase was assayed (Table 1). On the other two occasions, maximal activity was obtained in the presence of acyl-carrier protein. For $\boldsymbol{M}$. avium, maximal activity was always obtained with $\alpha$-cyclodextrin.

\section{Malonyl-CoA-dependent, fatty acyl-CoA elongation activity in $M$, microti and $M$. avium}

For $M$. avium there was little difference in activities between extracts from bacteria no matter how they were grown (Table 5).

With either decanoyl-CoA or palmitoyl-CoA as the primer, activities were slightly lower in extracts from $M$. avium grown in Dubos medium plus palmitate than activities in $M$. avium grown in Dubos medium alone. However, these elongase activities were approximately equal or higher in M. avium grown in mice (Table 5) than the activities in $M$. avium grown in Dubos medium alone.

In extracts of $M$. microti, activity with decanoyl-CoA as primer was diminished if the bacteria had been grown in the presence of lipids or in mice. Palmitoyl-CoAdependent elongation, however, was not significantly diminished in M. microti grown in mice (Table 5). The complete lack of malonyl-CoA-dependent, fatty acylCoA elongation activity in extracts of $M$. microti, grown in the presence of palmitate, may be a result of the severe $(60 \%)$ inhibition of growth caused by the fatty acid.

There was no clear requirement apparent for either acyl-carrier protein or $\alpha$-cyclodextrin when assaying for the activities described. However, in all the assays done with $M$. microti and $M$. avium, either acyl-carrier protein or $\alpha$-cyclodextrin was needed for maximal activity with $92 \%$ of the extracts prepared.
Acetyl-CoA-dependent, fatty acyl-CoA elongation activity in $M$. microti and $M$. avium

Acetyl-CoA-dependent fatty acyl-CoA elongation was the major elongase activity in $M$. leprae (Table 3 ). In none of the three mycobacteria studied was this activity related to the growth rate. Mean generation times for growth in vivo are approximately $12 \mathrm{~d}$ for $M$. leprae (Levy, 1976) and approximately $24 \mathrm{~h}$ for $M$. microti and $M$. avium, but acetyl-CoA-dependent elongase activity in extracts from these three mycobacteria grown in host tissues were in the approximate ratio $1: 3: 1$. In both $M$. avium and $M$. microti (Table 6), elongation of both decanoyl-CoA and palmitoyl-CoA, as primers, was about four times higher in extracts from bacteria grown in mice, or from bacteria grown in Dubos medium with added lipids, than in extracts from bacteria grown in Dubos medium alone.

Table 5. Malonyl-CoA-dependent fatty acyl-CoA elongase in $M$. microti and $M$. avium

Assay mixtures and conditions were as in Table 1. Values (means \pm SEM) are pmol malonyl-CoA incorporated into fatty acid $\mathrm{min}^{-1}$ (mg protein) $)^{-1}$.

\begin{tabular}{llcc}
\hline & & \multicolumn{2}{c}{ Primer } \\
\cline { 3 - 4 } $\begin{array}{l}\text { Extract } \\
\text { from: }\end{array}$ & \multicolumn{1}{c}{$\begin{array}{c}\text { Growth } \\
\text { medium }\end{array}$} & Decanoyl-CoA & Palmitoyl-CoA \\
\hline M. microti & Dubos & $110 \pm 35$ & $131 \pm 55$ \\
& Dubos + liposomes & $11 \pm 4$ & $42 \pm 17$ \\
& Dubos + palmitate & $0 \pm 6$ & $0 \pm 5$ \\
& Mice & $13 \pm 6$ & $106 \pm 30$ \\
M. avium & $11 \pm 3$ & $45 \pm 11$ \\
& Dubos & $6 \pm 2$ & $15 \pm 5$ \\
& Dubos + palmitate & $21 \pm 8$ & $37 \pm 14$ \\
\hline
\end{tabular}

Table 6. Acetyl-CoA-dependent fatty acyl-CoA elongase in $M$. microti and $M$. avium

Assay mixtures and conditions were as in Table 1. Values (means \pm SEM) are pmol acetyl-CoA incorporated into fatty acid $\mathrm{min}^{-1}$ (mg protein $)^{-1}$.

\begin{tabular}{llcc}
\hline & & \multicolumn{2}{c}{ Primer } \\
\cline { 3 - 4 } Extract & \multicolumn{1}{c}{$\begin{array}{c}\text { Growth } \\
\text { medium }\end{array}$} & Decanoyl-CoA & Palmitoyl-CoA \\
\hline \multirow{2}{*}{ M. microti } & Dubos & $148 \pm 42$ & $70 \pm 33$ \\
& Dubos + liposomes & $688 \pm 112$ & $422 \pm 51$ \\
& Dubos + palmitate & $490 \pm 70$ & $330 \pm 60$ \\
& Mice & $851 \pm 120$ & $310 \pm 20$ \\
M. avium & Dubos & $80 \pm 7$ & $27 \pm 11$ \\
& Dubos + palmitate & $291 \pm 68$ & $99 \pm 25$ \\
& Mice & $395 \pm 157$ & $101 \pm 25$ \\
\hline
\end{tabular}




\section{Discussion}

The three pathogenic mycobacteria studied here $-M$. avium, M. microti and $M$. leprae - all produced fatty acid synthetase as well as at least two elongases of the malonyl-CoA- and acetyl-CoA-dependent types. Activities were assayed in the presence of $\alpha$-cyclodextrin or acyl-carrier protein in an attempt to distinguish between enzyme systems. Since $\alpha$-cyclodextrin envelops fatty acids it protects enzyme systems which are inhibited by fatty acids or fatty acyl-CoAs, such as the de novo fatty acid synthetase in $M$. smegmatis, which is $>90 \%$ inhibited by $3 \mu \mathrm{M}$ fatty acyl-CoA (Bloch, 1977). Acylcarrier protein stimulates the loosely aggregated systems found in most bacteria: in mycobacteria these appear restricted to malonyl-CoA-dependent elongases (Bloch, 1977; Medhi et al., 1979; Ratledge, 1982). However, while $\alpha$-cyclodextrin usually stimulated the de novo synthetase activity studied in this work, it appeared that $\alpha$-cyclodextrin and acyl-carrier protein could substitute for one another in stimulating malonyl-CoA-dependent elongases, perhaps simply acting by binding the fatty acyl-CoA.

Decanoyl-CoA was included in assays for elongases, as many mycobacterial elongases have considerable activity with $C_{8}$ to $C_{12}$ acids (Kusaka, 1977; Medhi et al., 1979). The general impression from Table 5 is that the malonyl-CoA-dependent elongase activity is greater with palmitoyl-CoA than with decanoyl-CoA, and that possibly in $M$. microti, decanoyl-CoA and palmitoyl-CoA elongation is catalysed by different enzymes, so great is the difference in the ratio of these activities between $M$. microti grown in Dubos medium and $M$. microti grown in mice.

It is, however, acetyl-CoA-dependent elongase activity that is the major elongase activity in $M$. leprae : as in $M$. microti grown in the presence of palmitate (which inhibits its growth), it may be that low activity of malonyl-CoA-dependent elongase activity is associated with slow growth.

Since acetyl-CoA-dependent elongase activity (Table 6), but not malonyl-CoA-dependent elongase activity (Table 5), is elevated when mycobacteria are grown in the presence of lipid, it appears that acetyl-CoAdependent, fatty acyl-CoA elongation is the activity involved in the response to an exogenous supply of lipids. This is the case at least with fatty acyl chains up to 16 carbon atoms in length, whether these are supplied in axenic culture medium or present in host cells. AcetylCoA-dependent elongase in host-grown mycobacteria was elevated to activity similar to that found in the corresponding mycobacteria grown in the presence of lipid, suggesting that mycobacteria respond to lipids present in the host. Activity of acetyl-CoA-dependent elongase was always higher with decanoyl-CoA than with palmitoyl-CoA; the ratio of activity with the two primers was similar (between $3: 1$ and $4: 1$ for $M$. avium, and between $1 \cdot 5: 1$ and $2 \cdot 7: 1$ for $M$. microti) regardless of how the bacteria were grown (Table 6), suggesting that the same enzyme system is involved, but that it has higher activity with the shorter chain fatty acyl-CoA.

While acetyl-CoA-dependent elongase activity was enhanced as a response to exogenous lipid, de novo fatty acid synthetase activity was depressed. The depression of synthetase activity was less severe in host-grown mycobacteria than in the corresponding mycobacteria grown with a source of lipid, but was still apparent (Table 4). Thus, while fatty acid synthetase activity in $M$. leprae is exceptionally low compared with its reported activity in other mycobacteria [see Bloch (1977) and Medhi et al. (1979) for comparisons], this may be a result of its growth in host cells where lipids are available. Any fatty acids released from those lipids and taken up into the mycobacterial cells would probably inhibit or repress fatty acid synthetase. Such metabolic control of fatty acid synthetase occurs in both $M$. microti and $M$. avium grown in vivo. Control of fatty acid synthetase activities in response to the growth environment appears to be at the level of expression of enzyme protein, since synthetase activities in all the mycobacteria studied here were obtained in the presence of $\alpha$-cyclodextrin, which, by enveloping fatty acids, removes the effect of the only known feedback inhibitor of mycobacterial fatty acid synthetase (Bloch, 1977). Moreover, removal of further possible feedback inhibitors by desalting extracts did not enhance synthetase activity.

The low activity of fatty acid synthetase in $M$. leprae has implications for its growth in vivo and in axenic culture. Mycobacteria contain about one-third of their dry weight as lipid, and about one-quarter as protein. With this information, values for fatty acid synthetase activity (Table 3 ) can be converted to pg lipid synthesized $\min ^{-1}(\mathrm{mg} \text { bacteria })^{-1}$, given that each molecule of malonyl-CoA incorporated will be as a $\left(\mathrm{CH}_{2}\right)_{2}$ unit in fatty acyl moieties of lipids. [This can give only a rough estimate as fatty acyl chains become modified, e.g. by desaturation or oxygenation - see Minnikin (1982).] Then it can be calculated how long it would take a population of $M$. leprae to fulfil the lipid requirements sufficient to double that population. Relying entirely on de novo fatty acid biosynthesis (Table 3 ) it would take $23 \mathrm{~d}$ for $M$. leprae to synthesize sufficient lipid for the cells to double in numbers. However, the mean generation time for $M$. leprae is $12 \mathrm{~d}$ (Levy, 1976), so the measured rate of de novo synthesis does not provide $M$. leprae with sufficient fatty acid for its growth. Hence, $M$. leprae requires an exogenous source of fatty acid.

Extrapolation from activities measured in cell extracts 
to the requirements of intact, living microbes can be misleading as the measured activities may not be representative of activities in the intact microbes. However, when $M$. microti and $M$. avium are grown in Dubos medium, where they must rely on fatty acid biosynthesis, the measured rates of de novo synthesis (Table 4) would provide them with sufficient lipid to double their population every $6 \cdot 1 \mathrm{~h}$ and $5 \cdot 2 \mathrm{~h}$, respectively. Since their mean generation time in this medium is about $24 \mathrm{~h}$ (Chadwick, 1982; Wheeler, 1987a), fatty acid biosynthesis does not limit their growth rate, and thus the validity of the conclusion that fatty acid biosynthesis de novo is not sufficient to support the lipids requirements of $M$. leprae is supported, albeit indirectly.

As an exogenous source of fatty acid, free fatty acids as such are unlikely to be a suitable source for growth - they are toxic to most mycobacteria (Saito et al., 1984), as well as the host in which they grow. Free fatty acids are scarce in animal tissues although phospholipids and acylglycerols are present in host cells and may provide a source of fatty acids if $M$. leprae can hydrolyse them to release the fatty acyl moieties (Barclay \& Wheeler, 1989). For axenic culture, a source of lipid appears to be necessary for isolation of $M$. leprae. Indeed, many slow-growing mycobacteria are isolated efficiently on media containing phosphatidylcholine. However, unlike some parasitic microbes, e.g. the protozoa Giardia lamblia (Gillin et al., 1986) and Trichomonas vaginalis (Peterson \& Alderete, 1984), $M$. leprae is not absolutely dependent on a supply of exogenous lipids to supply a fatty acids. Should $M$. leprae be cultivated axenically, it may ultimately be possible to grow it without a source of fatty acid so long as de novo fatty acid synthesis could be induced or derepressed, as occurs in $M$. microti and $M$. avium grown without added lipids (Table 3 ). The results presented here are consistent with the hypothesis that pathogenic mycobacteria, including $M$. leprae, scavenge (fatty acids derived from) acyllipids when growing inside host cells.

P. R.W. is grateful to the MRC and the UNDP/World Bank/WHO Special Programme for Research and Training in Tropical Diseases for financial support during the course of this investigation. LEPRA and the WHO (IMMLEP programme) provided funds for the maintenance of armadillo colonies.

\section{References}

AsCenzi, J. M. \& Vestal, V. R. (1979). Regulation of fatty acid biosynthesis by carbon substrates in Mycobacterium convolutum. Journal of Bacteriology 137, 384-390.
BARCLAY, R. \& WheELER, P. R. (1989). Metabolism of mycobacteria in tissues. In The Biology of the Mycobacteria, vol. 3, pp. 37-106. Edited by C. Ratledge, J. Stanford \& J. M. Grange. London: Academic Press.

BLOCH, K. (1975). Fatty acid synthetases from Mycobacterium phlei. Methods in Enzymology 35, 85-90.

BLOCH, K. (1977). Control mechanisms for fatty acid synthesis in Mycobacterium smegmatis. Advances in Enzymology 45, 1-84.

CHADWICK, M. V. (1982). Mycobacteria. Institute of Medical Laboratory Sciences Monographs. Bristol: P. S. G. Wright.

Gillin, F. D., Gaulton, J., Hoffmann, A. F., Gurantz, D. \& Sauch, J. F. (1986). Biliary lipids support serum-free growth of Giardia lamblia. Infection and Immunity 53, 641-645.

Kondo, E., Suzuki, K., KanaI, K. \& Yasuda, T. (1985). Liposomesmycobacteria incubation systems as a partial model of host-parasite interaction at cell membrane level. Japanese Journal of Medical Science and Biology 38, 169-180.

KUSAKA, T. (1977). Fatty acid synthesizing enzyme activity of cultured Mycobacterium lepraemurium. International Journal of Leprosy 45, $132-144$.

LEVY, L. (1976). Studies in the mouse footpad technique for cultivation of Mycobacterium leprae. 3. Doubling time during logarithmic multiplication. Leprosy Review 47, 103-106.

Medhi, J., Murthy, P. S. \& Venkitasubramanian, T. A. (1979). Demonstration and purification of three fatty acid synthetases from Mycobacterium tuberculosis $\mathrm{H}_{37}, \mathbf{R}_{v}$. Indian Journal of Biochemistry and Biophysics 16, 216-222.

MinNikin, D. E. (1982). Lipids: complex lipids, their chemistry, biosynthesis and roles. In The Biology of the Mycobacteria, vol. 1, pp. 95-184. Edited by C. Ratledge \& J. Stanford. London: Academic Press.

MoR, N. (1983). Intracellular location of Mycobacterium leprae in macrophages of normal and immunodeficient mice and effect of rifampicin. Infection and Immunity 42, 802-811.

MUKHERJEE, R. M. \& ANTIA, N. H. (1985). Intracellular multiplication of leprosy-derived mycobacteria in Schwann cells of dorsal root ganglion cultures. Journal of Clinical Microbiology 21, 208-212.

Peterson, K. M. \& Alderete, J. F. (1984). Trichomonas vaginalis is dependent on uptake and degradation of human low density lipoproteins. Journal of Experimental Medicine 160, 1261-1272.

RATLEDGE, C. (1982). Lipids: cell composition, fatty acid biosynthesis. In The Biology of the Mycobacteria, vol. 1, pp. 53-93. Edited by C. Ratledge \& J. Stanford. London: Academic Press.

Saito, H., Tomioka, H. \& Yoneyama, T. (1984). Growth of Group IV mycobacteria on medium containing various saturated and unsaturated fatty acids. Antimicrobial Agents and Chemotherapy 26, 164169.

WHEELER, P. R. (1987a). Biosynthesis and scavenging of purines by pathogenic mycobacteria including Mycobacterium leprae. Journal of General Microbiology 133, 2999-3011.

WHEELER, P. R. (1987b). Enzymes for purine synthesis and scavenging in pathogenic mycobacteria and their distribution in Mycobacterium leprae. Journal of General Microbiology 133, 3013-3018.

WhEeler, P. R. \& GRegory, D. (1980). Superoxide dismutase, peroxidatic activity and catalase in Mycobacterium leprae purified from armadillo liver. Journal of General Microbiology 121, 457-464.

W HEELER, P. R. \& RATLEDGE, C. (1988). Use of carbon sources for lipid biosynthesis in Mycobacterium leprae: a comparison with other pathogenic mycobacteria. Journal of General Microbiology 134, 2111-2121

Wheeler, P. R., BharadWaJ, V. P. \& Gregory, D. (1982). $N$-Acetyl$\beta$-glucosaminidase, $\beta$-glucoronidase and acid phosphatase in $M y c o-$ bacterium leprae. Journal of General Microbiology 128, 1063-1071.

WORLD Health ORganization (1980). UNDP/World Bank/WHO Special Programme for Research and Training in Tropical Diseases. Report of the Fifth Meeting on the Immunology of Leprosy (IMMLEP). TDR/IMMLEP-SWG (5)/80.3, Annex 4, p. 23. Geneva: World Health Organization. 